\title{
Panniculitis in systemic diseases: A two cases report
}

\section{Nouha Ghriss ${ }^{1}$, Sameh Sayhi', Sameh Mezri², Nour Gueddiche', Nadia Ben Abdelhafidh', Faida Ajili', Bassem Louzir ${ }^{1}$}

${ }^{1}$ Internal Medicine Department, Research Unit Systemic diseases (RU17DN02). Military Hospital of Tunis, Tunis, Tunisia, ${ }^{2}$ ENT Department. Military Hospital of Tunis, Tunis, Tunisia

Corresponding author: Dr. Sameh Sayhi, E-mail: sameh_sayhi@yahoo.fr

\begin{abstract}
Panniculitis is an inflammatory disease of subcutaneous adipose tissue which is rarely associated with systemic diseases. In most cases, the evolution of panniculitis associated with these affections is favorable with corticosteroids and/or immunosuppressants. We report 2 cases of patients who were followed for systemic diseases associated with panniculitis. The first case concerned a patient followed for Behçet's disease and the second case was related to dermatomyositis diagnosed concomitantly with panniculitis. Many etiologies of panniculitis have been reported. It is an uncommon cutaneous manifestation of connective tissue diseases and vasculitis. The occurrence of panniculitis may precede or be concomitant with systemic diseases.
\end{abstract}

Key words: Panniculitis; Dermatomyositis; Behçet disease

\section{INTRODUCTION}

Panniculitis is a group of heterogeneous disease caused by inflammation of subcutaneous adipose tissue. Many etiologies including trauma, physical, infectious and sometimes systemic disease may be responsible for this condition.

In this work, we will report 2 cases of panniculitis occur during systemic diseases.

\section{CASE REPORT}

\section{Case 1}

We report the case of 53 year old patient with history of central diabetes insipidus, followed since April 2015 for abdominal pain, general signs (weight loss and fever) and mesenteric panniculitis. Infectious and neoplasic etiologies were eliminated. The patient was treated by corticosteroids $(60 \mathrm{~m} /$ day $)$. He was readmitted in the internal medicine department after one month for motor deficit of lower limbs with installation of psychic manifestations when he was under $45 \mathrm{mg} /$ day of corticosteroids.

Clinical examination objectified bilateral kinetic cerebellar syndrome, pyramidal syndrome and spinal cord syndrome. A series of exploration was conducted.

He had an inflammatory syndrome (CRP: $60 \mathrm{mg} / \mathrm{L}$ and VS: $100 \mathrm{mmHl}$ ) and leukocytosis at $13400 \mathrm{cells} / \mathrm{mm}^{3}$. The immunological tests were normal: antinuclear antibody, Anti-neutrophil cytoplasmic antibodies were negative, complement levels (C3 and $\mathrm{C} 4)$ were normal. Electromyogram and Wallpaper eye were also normal.

A lumbar puncture was performed showing normal cytology and chemistry, negative culture and negative research of neoplastic cells and antibody antineuronals.

Body tomodensitometry showed abdominal and retroperitoneal panniculitis infiltration without adenomegaly. Pathological examination of the biopsy tissue panniculitis showed fibro adipose and

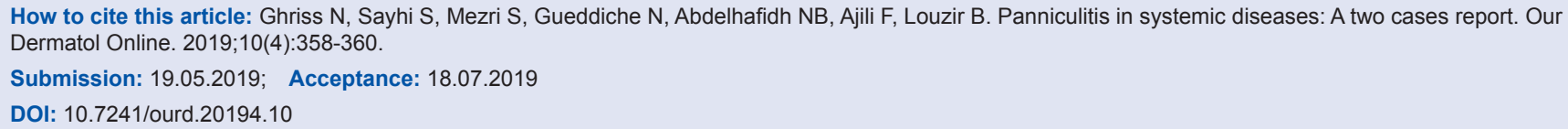


steatonecrosis lesions without signs of malignancy; with negative Immunohistochemistry: CD3 and CD20.

Brain MRI objectified diffuse signal abnormalities: at the posterior fossa white matter, gray matter, brain stem and periventricular. The bone marrow biopsy was normal.

The infectious including tuberculosis was ruled out at the lack of clinical arguments, the tuberculin skin test was negative and the evolution of a few months was against this diagnosis.

Lymphoma was reversed before the negativity of the immunohistochemical study and bone marrow biopsy was not in favor.

Neurobehçet was strongly suspected in the inaugural neurological involvement, achievement of the posterior fossa and the notion of oral an genital aphthosis with pseudofolliculitis in clinical examination.

The patient was treated by intravenous methylprednisolone $\mathrm{lg}$ /day relayed by prednisone $1 \mathrm{mg} / \mathrm{kg} /$ day associated with $\mathrm{lg}$ of cyclophosphamide with partial improvement in muscle strength, and psychic signs.

When patient was readmitted for $3^{\text {rd }}$ cure of cyclophosphamide, he presented a deep venous thrombosis of the left lower limb complicated by massive pulmonary embolism generating a cardio respiratory arrest not recovered by resuscitation.

\section{Case 2}

We report the case of 47 year old women who was hospitalized for myalgia, motor deficit and erythematous subcutaneous nodules appearing in upper and lower limbs (Fig. 1).

Clinical examination objectified proximal muscular weakness. Routine laboratory tests revealed slight increases in the serum levels of CRP and muscle enzymes (CPK at 2120UI/L). Full blood count was normal. Immunology work-up were negative. Skin biopsy with histological examination showed inflammatory adipose tissue infiltrated by polynuclear cells (Fig. 2) evoking panniculitis. Clinical and electromyogram findings concluded to dermatomyositis diagnosis associated to panniculitis. Patient was treated initially with nonsteroidal anti-inflammatory drugs and methotrexate

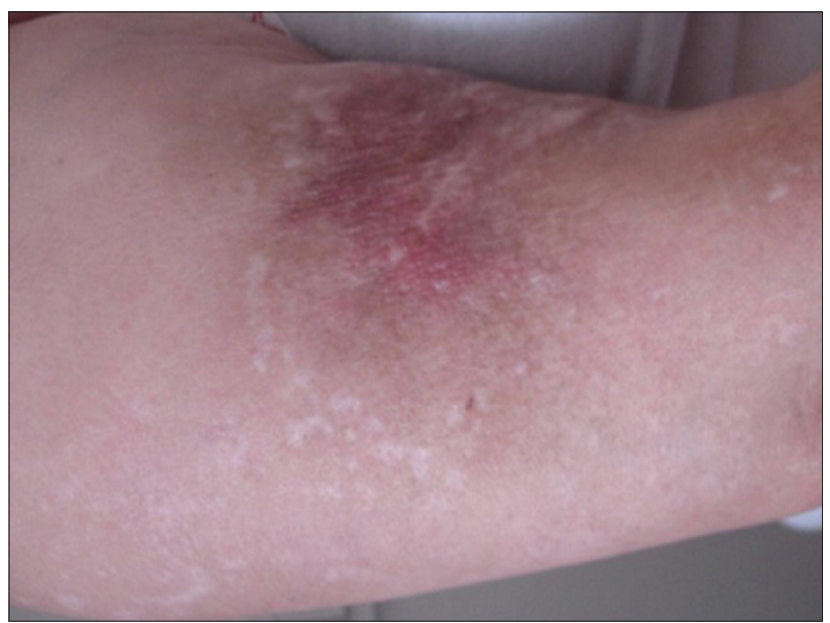

Figure 1: Erythematous dermo-hypodermic nodules of panniculitis in the arm in patient with dermatomyositis.

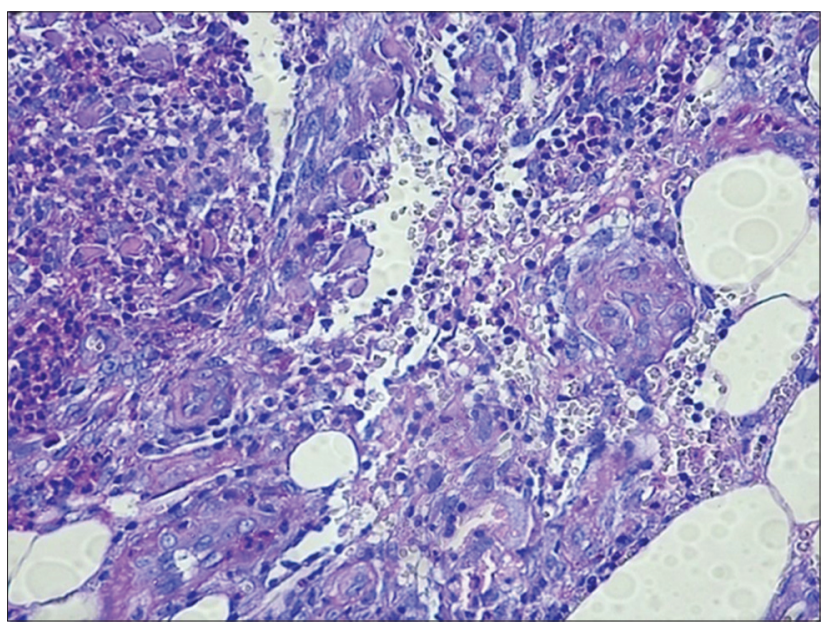

Figure 2: Inflammatory adipose tissue infiltrated by polynuclear cells in patient with dermatomyositis, HE x 400 .

$25 \mathrm{mg}$ /day with partial clinical response. Patient then received immunoglobulin $2 \mathrm{~g} / \mathrm{kg} /$ cure with favorable outcome.

\section{DISCUSSION}

The elementary lesion of panniculitis is a painful nodule with dermohypodermic extension. The main components of the hypodermis are lobules, septa and vessels. They will allow classifying panniculitis according to predominant inflammation of any of the three components.

Erythema nodosum is the most frequent septal panniculitis. It does not require biopsy in its typical clinical presentation. It is a painful dermohypodermal nodules, asymmetrically affecting the two legs and taking blue and yellowish contusiform aspects, always healing without sequelae in 10 to 15 days. 
Lobular panniculitis most often occurs where the fat panniculus is thick. Unlike erythema nodosum, they can leave a very characteristic depressed scar.

The diagnosis is oriented by the distribution of cutaneous involvement, and also by the consistency, size and sensitivity of the lesions. In most common cases, the specific diagnosis based on histological data [1-3].

Many etiologies including trauma, physical, infectious and sometimes systemic disease may be responsible for this condition [4].

Dermatomyositis is an inflammatory autoimmune muscle disease. Panniculitis is rarely observed during dermatomyositis. The first case of dermatomyositispanniculitis was described in 1924 by Weber and Gray in a 22-year-old woman and since then only about 20 sporadic cases have been reported since then including cases associated with juvenile dermatomyositis. Its pathogenesis remains obscure. Panniculitis can appear at the same time or before the other manifestations of dermatomyositis. its occurrence can be delayed up to 5 years after the diagnosis of dermatomyositis [5-7]. I our case, dermatomyositis was diagnosed concomitantly with panniculitis.

Behçet syndrome is a multisystemic vasculitis involving the skin, mucosa, eyes, joints, nervous, cardiovascular, and gastrointestinal system. Nodular lesions are rather common in Behçet syndrome [8]. Panniculitis is exceptional during Behçet's disease. the literature has reported only a few sporadic cases $[9,10]$.

\section{CONCLUSION}

Panniculitis is a group of heterogeneous inflammatory diseases that involve the subcutaneous fat. A biopsy is needed to establish an accurate diagnosis. The subcutaneous fat may be involved secondarily in trauma, deep cutaneous fungal infections, and many malignancies. It also important to remember that panniculitis can occur in vasculitis and connective tissue diseases.

\section{Consent}

The examination of the patient was conducted according to the Declaration of Helsinki principles.

\section{REFERENCES}

1. Requena L, Yus ES. Panniculitis. Part I. Mostly septal panniculitis. J Am Acad Dermatol. 2001;45:163-86.

2. Joshi V. Panniculitis. Indian J Rheumatol. 2007;2:147-55.

3. Requena L, Yus ES. Panniculitis. Part II. Mostlylobularpanniculitis. J Am Acad Dermatol. 2001;45:325-64.

4. Wick MR. Panniculitis: A summary. Sem Diag Pathol. 2017;34:261-72.

5. Girouard SD, Velez NF, Penson RT, Massarotti EM, Vleugels RA. Panniculitis Associated with dermatomyositis and recurrent ovarian cancer. Arch Dermatol. 2012;148:740-4.

6. Abdelhafidh NB, Toujeni S, Kefi A, Bousetta N, Sayhi S, Gharsallah I, et al. Dermatomyosite et panniculite: place des immunoglobulines. Pan Afr Med J. 201629;23:262.

7. Calle A, Linos K, Sangueza O, Cerroni L, Carlson JA, Requena L, et al. Dermatomyositispanniculitis: A case series and review of the literature. J Am Acad Dermatol. 2018;79(3, Supplement 1):AB104.

8. Akdeniz N, Elmas ÖF, Karadă̆ AS. Behçetsyndrome: A greatimitator. Clinics in Dermatology [Internet]. 11 janv 2019 [cité 17 mai 2019]; Disponible sur: http://www.sciencedirect.com/ science/article/pii/S0738081X1930001X

9. Demirkesen C, Tüzüner N, Mat C, Senocak M, Büyükbabani N, Tüzün Y, etal. Clinicopathologicevaluation of nodularcutaneouslesions of Behçet syndrome. Am J Clin Pathol. 2001;116:341-6.

10. Ohtake N, Kanekura T, Kawamura K, Kanzaki T. Unusualpolyp-like structures in lobularpanniculitis of a patient withBehçet'sdisease. Am J Dermatopathol. 1997;19:185-8.

Copyright by Nouha Ghriss, et al. This is an open-access article distributed under the terms of the Creative Commons Attribution License which permits unrestricted use, distribution, and reproduction in any medium, provided the original author and source are credited.

Source of Support: Nil, Conflict of Interest: None declared. 